\title{
Интеркалирование молекул фуллерена $\mathrm{C}_{60}$ под однослойный графен на карбиде молибдена
}

\author{
(C) E.В. Рутьков, Н.Р. Галль
}

Физико-технический институт им. А.Ф. Иоффре Российской академии наук, 194021 Санкт-Петербург, Россия

E-mail: rutkov@ms.ioffe.ru, Gall@ms.ioffe.ru

(Получена 22 января 2018 г. Принята к печати 31 января 2018 г.)

Показано, что прогрев пленки фуллерита толщиной в несколько мономолекулярных слоев, напыленной на однослойный графен, образованный на подложке из карбида молибдена $\mathrm{Mo}_{2} \mathrm{C}$, при температуре $T=700-800 \mathrm{~K}$ приводит к интеркалированию молекул $\mathrm{C}_{60}$ под графеновый слой. Прямое напыление молекул $\mathrm{C}_{60}$ при $T=650 \mathrm{~K}$ также приводит к интеркалированию молекул $\mathrm{C}_{60}$ под графен; максимальное количество фуллерена, накопленного под графеном, составляет один монослой.

DOI: $10.21883 /$ FTP.2018.09.46157.8824

\section{1. Введение}

В наших работах $[1,2]$ обнаружен и исследован эффект интеркалирования графеновых пленок на металлах чужеродными атомами. В дальнейшем этот эффект был детально изучен применительно к многим атомам ( $\mathrm{Na}$, $\mathrm{K}, \mathrm{Cs}, \mathrm{Si}, \mathrm{C}, \mathrm{Mo}, \mathrm{Al}, \mathrm{Ag}, \mathrm{Ba}, \mathrm{Ir}, \mathrm{Cu}, \mathrm{Pt})$ для графена на разных металлических подложках: $\operatorname{Re}(1010), \mathrm{Rh}(111)$, $\mathrm{Ni}(111), \operatorname{Ir}(111)$ [2,3]. Предложен механизм интеркалирования через дефекты графенового слоя [2].

В работах $[4,5]$ показана возможность интеркалирования графена на $\operatorname{Ir}(111)$ и $\operatorname{Re}(1010)$ молекулами $\mathrm{C}_{60}$, что представляет большой практический интерес, так как позволяет изолировать графен от металлической подложки. В частности, попытка изолировать графен от металла предпринималась во многих работах с помощью интеркалирования кислорода под графен с целью создания диэлектрического окисного слоя [6-8].

Число публикаций, связанных с интеркалированием графена, постоянно растет, где в качестве подложки используется не только металл, но и карбид кремния [9-14]. В связи с этим важным представляется вопрос о влиянии подложки на процесс интеркалирования, в частности вопрос о том, в какой мере обнаруженные ранее закономерности справедливы при использовании карбида металла вместо самого металла.

В данной работе изучается интеркалирование молекулами $\mathrm{C}_{60}$ графена на карбиде молибдена $\mathrm{Mo}_{2} \mathrm{C}$.

\section{2. Методы эксперимента}

Опыты проводили в сверхвысоковакуумном (остаточное давление $P \sim 10^{-10}$ Торр) оже-спектрометре высокого разрешения (энергетическое разрешение $\Delta E / E \sim 0.1 \%$ ) с призменным энергоанализатором, в котором поверхностные слои изучали методом электронной оже-спектроскопии (ЭОС). Имелась возможность записывать оже-спектры непосредственно с нагретых образцов в интервале температур 300-2000 K, что в ряде случаев имело принципиальное значение, поскольку состояние углеродной пленки существенно зависит от температуры [2].
В установке имелся модуль, позволяющий реализовать комбинированный метод термоэлектронной эмиссии и поверхностной ионизации [3]. В частности, был использован метод зондирования поверхности потоком молекул $\mathrm{CsCl}$, который крайне чувствителен к качеству (дефектности) графенового слоя [2,3].

Образцами служили прямонакальные молибденовые ленты размерами $0.02 \times 1 \times 40$ мм, которые очищались и характеризовались по стандартной процедуре [15]. Ленты текстурировались, и на поверхность выходила грань (100) с работой выхода $е \varphi=4.4$ э, поверхность была однородной по работе выхода. Данные электронномикроскопических исследований дали средний размер зерен $\sim 15$ мкм.

Фуллерены чистотой 99.5\% напылялись на всю поверхность ленты из кнудсеновской ячейки. Плотность потока $v_{\mathrm{C}_{60}}$ была абсолютно калибрована. В качестве оже-эталона использовали слой графена на $\operatorname{Ir}(111)$, содержащий атомов углерода $N_{\mathrm{CM}}=3.86 \cdot 10^{15} \mathrm{~cm}^{-2}$ (1 монослой). При этом иридиевая лента располагалась рядом с молибденовой, а напыляемые на иридий при $300 \mathrm{~K}$ молекулы фуллерена $\mathrm{C}_{60}$ с малой степенью покрытия разлагались при $T \approx 900 \mathrm{~K}$, а полученный углеродный слой графитизировался при $T=1500 \mathrm{~K}$, сравнивались интенсивность оже-сигналов углерода от сплошного слоя графена на $\operatorname{Ir}(111)$ и от слоя графена, полученного в результате графитизации пленки фуллерита [15].

Для оже-анализа использовались пики углерода (энергия $E=269-272$ эВ) и молибдена $(E=221$ эВ). Интенсивный оже-пик молибдена оказался весьма информативным для анализа процессов в поверхностных углеродных слоях по степени изменения его интенсивности [15].

\section{3. Экспериментальные результаты}

\section{1. Образование графена на карбиде молибдена}

Для образования графена использовался традиционный для нас способ - крекинг на нагретом до тем- 
пературы $T_{\mathrm{C}}=1700 \mathrm{~K}$ образце напускаемых в прибор молекул $\mathrm{C}_{6} \mathrm{H}_{6}$. В работах [2,3] подробно описана методика образования слоя графена, его свойства и характеризация, в том числе приводятся доказательства, что образуется только один сплошной слой графена. На нагретом до $T_{\mathrm{C}}=1700 \mathrm{~K}$ молибдене молекулы бензола диссоциируют, водород десорбируется, а атомы углерода растворяются в объеме металла. Процесс науглероживания проходит следующие фазы: формирование на поверхности карбида МоC, формирование в приповерхностной области объемного карбида $\mathrm{Mo}_{2} \mathrm{C}$ и его прорастание по всей толщине, завершающая стадия образование на поверхности сплошной пленки графена. На пассивной поверхности графена диссоциация молекул бензола прекращается, и толщина пленки в один слой сохраняется. Отметим, что разработанный нами метод зондирования графена молекулами $\mathrm{CsCl}$, крайне чувствительный к дефектности слоя, указывает на наличие дефектов на уровне $\sim 0.01 \%$ от всей площади образца: диссоциация молекул $\mathrm{CsCl}$ происходит

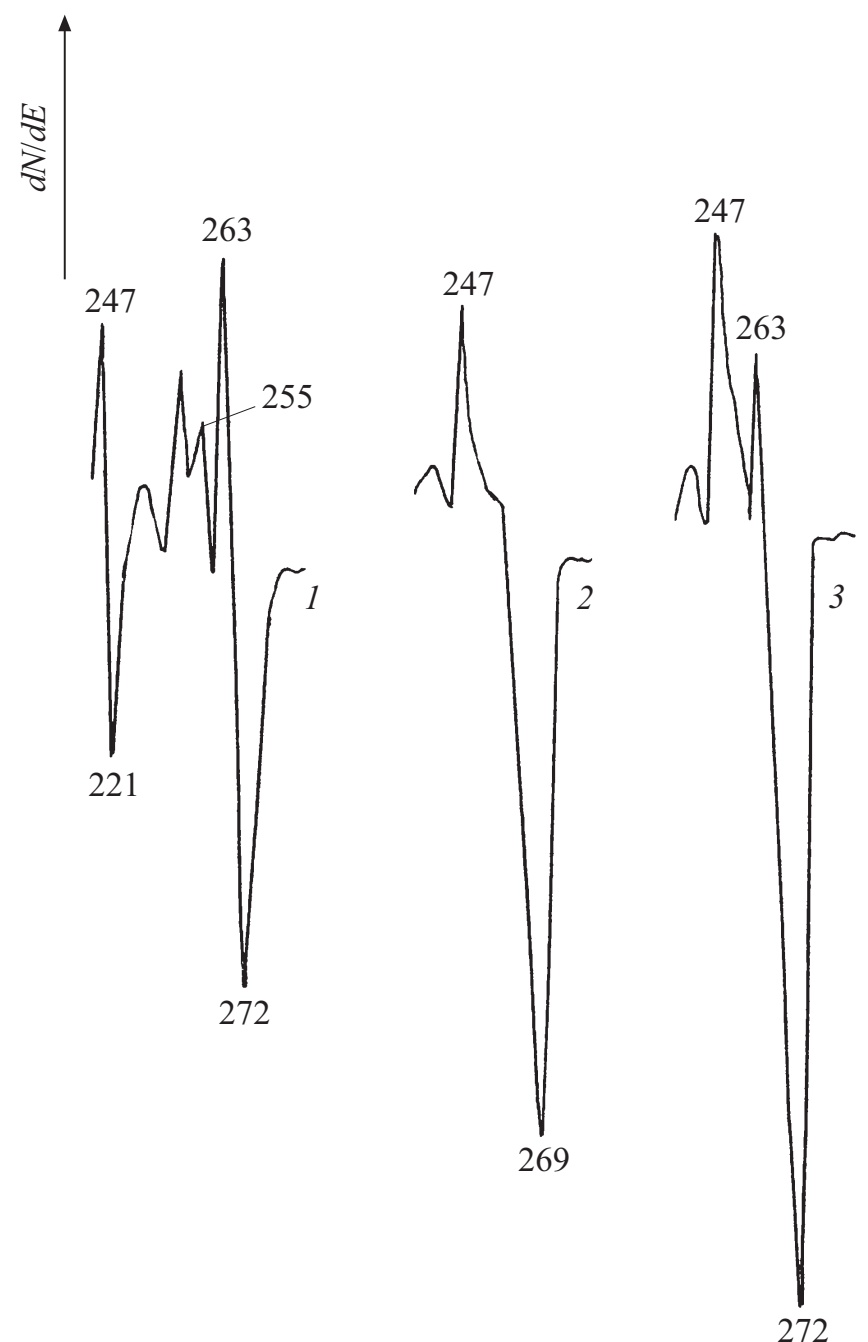

Рис. 1. Оже-спектры углерода от одного слоя графена на молибдене (1), от пленки фуллерита (2), от толстой пленки графита на молибдене (3). Указаны энергии пиков в эВ. только на дефектах слоя, один из продуктов диссоциации десорбируется в виде ионов $\mathrm{Cs}^{+}$и легко регистрируется. Поскольку на металлах графеновая пленка растет путем образования островков графена [15], разумно ожидать, что дефектами являются края слившихся островков графена, через которые и происходит интеркалирование графена атомами [2].

Полученный слой графена на карбиде молибдена обладает адсорбционными, эмиссионными, каталитическими и интеркаляционными свойствами, близкими к свойствам графена на других металлах ( $\mathrm{Ir}, \mathrm{Rh}, \mathrm{Re}$, $\mathrm{Ni}$, на которых получено в сканирующем туннельном микроскопе изображение атомной структуры пленки графена и показана ее сплошность $[16,17]$.

Изменения температуры науглероженного при $T_{\mathrm{C}}$ молибдена приводят к следующему. При $T>T_{\mathrm{C}}+70^{\circ} \mathrm{C}$ графен разрушается, атомы углерода растворяются в объеме $\mathrm{Mo}_{2} \mathrm{C}$. При понижении температуры до $T=T_{\mathrm{C}}$ на поверхности быстро восстанавливался слой графена путем выделения углерода из пересыщенного твердого раствора. При $T<T_{\mathrm{C}}-100^{\circ} \mathrm{C}$ на поверхности формируется толстая графитовая пленка. При $T \leq 1000 \mathrm{~K}$ выделение углерода прекращается, так как „замораживается“ диффузия атомов углерода в объеме образца. Резкое уменьшение температуры (выключение тока накала ленты) от $T_{\mathrm{C}}$ до комнатной сохраняет слой графена в диапазоне $300-1000 \mathrm{~K}$.

Отметим, что форма оже-спектра графена на карбиде $\mathrm{Mo}_{2} \mathrm{C}$ необычная и является результатом наложения оже-пиков углерода от графена, поверхностного карбида $\mathrm{MoC} \mathrm{и} \mathrm{объемного} \mathrm{карбида} \mathrm{Mo}_{2} \mathrm{C}[15]$ (рис. 1, спектр 1).

\section{2. Интеркалирование графена на карбиде $\mathrm{Mo}_{2} \mathrm{C}$ молекулами $\mathrm{C}_{60}$}

Чтобы интеркалировать молекулы $\mathrm{C}_{60}$ под пленку графена, воспользуемся двумя способами. Первый способ мы применяли ранее лишь для системы $\operatorname{Ir}(111)-г$ рафен. Для этого на графен при $300 \mathrm{~K}$ наносили пленку фуллерита толщиной $\sim 2$ слоя, получающийся оже-спектр типичен для фуллерита (рис. 1, спектр 2). Далее систему отжигали. На рис. 2 представлена зависимость ожесигнала углерода (кривая 1) и молибдена (кривая 2) от температуры подложки. Видно, что вначале ожесигнал подложки полностью подавлен. Это не удивительно, так как общая концентрация атомов углерода на поверхности $\sim 3 \cdot 10^{16} \mathrm{~cm}^{-2}$, что эквивалентно $\sim 7$ слоям графена, а это практически предельная чувствительность оже-спектроскопии по глубине анализа. Упрощенная схема-иллюстрация опыта представлена на рис. 3. Прогрев пленки до $T \approx 700 \mathrm{~K}$ приводит к следующему: большая часть молекул $\mathrm{C}_{60}$ десорбируется, а часть молекул $(\sim 25 \%)$ успевает промигрировать до дефектов слоя графена (краев островков) и перейти в интеркалированное состояние (рис. $3, b$ ). Наблюдаемая полка на рис. 2 в интервале температур 750-950 K соответствует сказанному выше. При этом интенсивность 


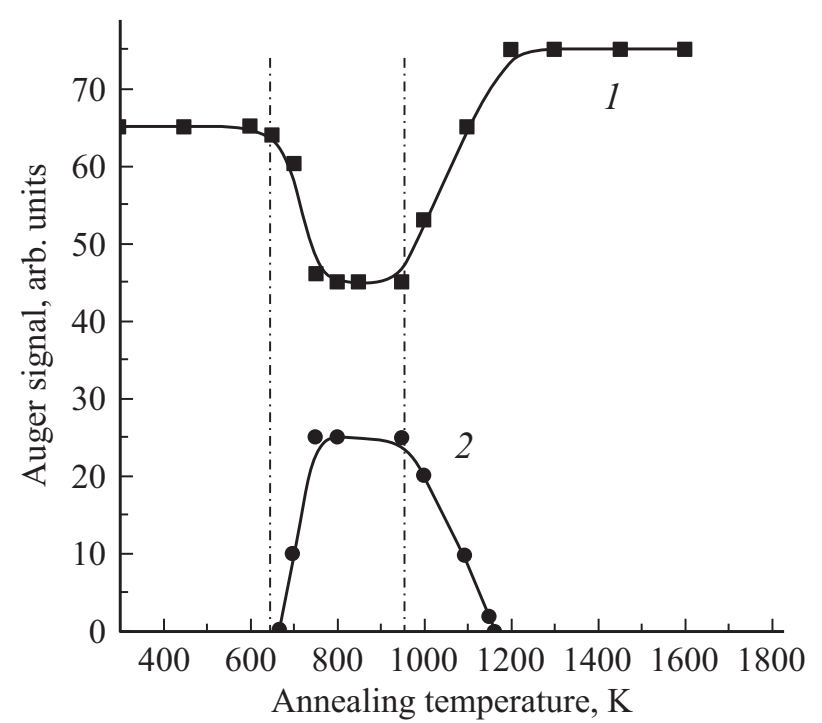

Рис. 2. Зависимости интенсивности оже-сигнала углерода (1) и молибдена (2) от температуры. Начальное состояние системы при $300 \mathrm{~K}$ - приблизительно два слоя из молекул фуллерена $\mathrm{C}_{60}$, нанесенных на графен, образованный на молибдене.

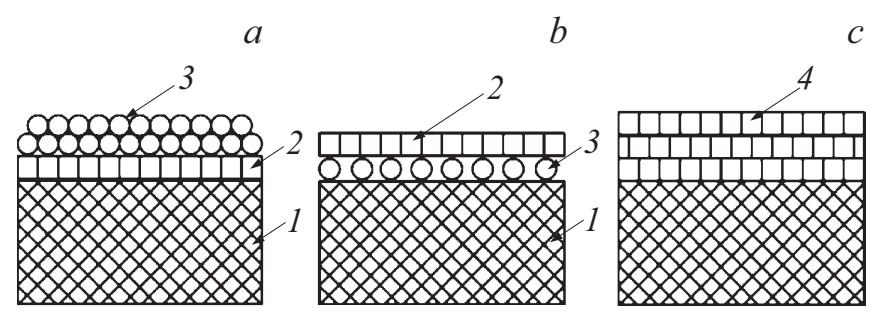

Рис. 3. Модельные представления начального состояния системы $(a)$, после прогрева при $T=750 \mathrm{~K}(b)$, после прогрева при $T=1200 \mathrm{~K}(c) .1$ - подложка (объемный карбид $\mathrm{Mo}_{2} \mathrm{C}$ ), 2 - графен, 3 - молекулы $\mathrm{C}_{60}, 4$ - графит.

оже-сигнала молибдена дополнительно ослабляется не только графеном, но и молекулами $\mathrm{C}_{60}$ под слоем графена. Если опыт провести заново, но с бо́льшим количеством напыленного при $300 \mathrm{~K}$ фуллерена, то при отжиге до 650-750 K под слой графена перейдет и большее количество молекул $\mathrm{C}_{60}$.

Оценим количество молекул $\mathrm{C}_{60}$, перешедших в интеркалированное состояние, использовав изменения интенсивности оже-сигнала молибдена $I_{\text {Мо только за счет }}$ молекул $\mathrm{C}_{60}$ :

$$
I_{\mathrm{Mo}}=I_{\mathrm{Mo}}^{0}(1-S)+k I_{\mathrm{Mo}}^{0} S,
$$

где $I_{\text {Мо }}^{0}-$ интенсивность оже-сигнала молибдена в отсутствие молекул $\mathrm{C}_{60}, k=1 / 4.5=0.22$ - экспериментально найденный коэффициент, связанный с уменьшением интенсивности оже-сигнала молибдена от одного сплошного слоя молекул $\mathrm{C}_{60}, S$ - относительная площадь, занятая молекулами $\mathrm{C}_{60}$. Из (1) найдем:

$$
S=\left(I_{\mathrm{Mo}}^{0}-I_{\mathrm{Mo}}\right) / I_{\mathrm{Mo}}^{0}(1-k) .
$$

Тогда концентрация молекул $\mathrm{C}_{60}$ под слоем графена будет равна

$$
N_{\mathrm{C}_{60}}=N_{\mathrm{C}_{60} \max } S \text {, }
$$

где $N_{\mathrm{C}_{60} \max }=2 \cdot 10^{14} \mathrm{~cm}^{-2}[4,5]$.

Максимальное количество молекул фуллерена, которые переходят в интеркалированное состояние, уменьшают интенсивность оже-сигнала молибдена в $~ 4.5$ раза, что, как показано в работе [4,5], соответствует их концентрации $\sim N_{\mathrm{C}_{60}} \approx 2 \cdot 10^{14} \mathrm{~cm}^{-2}$. Количество молекул в интеркалированном состоянии для рис. 2 соответствует $N_{\mathrm{C}_{60}} \sim 5 \cdot 10^{13} \mathrm{~cm}^{-2}$. При $T>900 \mathrm{~K}$ начинается диссоциация молекул $\mathrm{C}_{60}$, контактирующих под графеном с металлом [15], а полученная углеродная пленка графитизируется, оже-спектр углерода становится типичным для графита (рис. 1, спектр 3), а оже-сигнал подложки полностью подавляется (рис. 3,c). Это показывает, что экранирующая способность углерода зависит от его химической формы и увеличивается при переходе фуллеренов в графитовую форму.

Рассмотрим второй способ интеркалирования графена на $\mathrm{Mo}_{2} \mathrm{C}$ молекулами $\mathrm{C}_{60}$ - прямое напыление на графен молекул при некоторой температуре подложки, достаточной, чтобы обеспечить эффективную миграцию фуллеренов, но при этом не настолько высокой, чтобы молекулы $\mathrm{C}_{60}$ термически десорбировались.

На рис. 4 показано изменение оже-сигналов углерода и молибдена при напылении молекул $\mathrm{C}_{60}$ потоком $v_{\mathrm{C}_{60}}=7 \cdot 10^{12} \mathrm{~cm}^{-2} \cdot \mathrm{c}^{-1}$ на графен при $T=650 \mathrm{~K}$. Отметим, что при этой температуре молекулы $\mathrm{C}_{60}$ способны термически десорбироваться. Видно, что при временах $t>2$ мин получается полка, при этом оже-сигнал молибдена ослабляется в 4-5 раз, что соответствует одному слою молекул фуллеренов c $N_{\mathrm{C}_{60}}=2 \cdot 10^{14} \mathrm{~cm}^{-2}$ (отметим, что один слой графена на металлах ослабляет интенсивность оже-сигнала

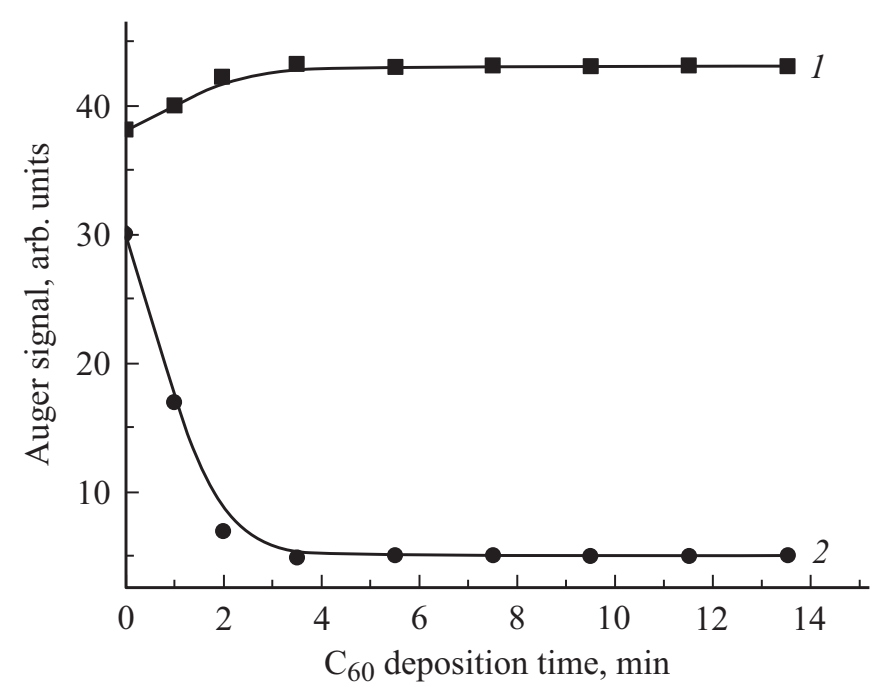

Рис. 4. Зависимости интенсивности оже-сигнала углерода (1) и молибдена (2) от времени напыления молекул $\mathrm{C}_{60}$ на графен при $T=650 \mathrm{~K}, v_{\mathrm{C}_{60}} \approx 7 \cdot 10^{12} \mathrm{~cm}^{-2} \cdot \mathrm{c}^{-1}$. 
подложки с $E=150-250$ эВ в 1.6 раза [15]). Общая доза упавших на поверхность молекул $\mathrm{C}_{60}$ равна $\quad N_{\mathrm{C}_{60}}=v_{\mathrm{C}_{60}} t=7 \cdot 10^{12} \cdot 120=8.4 \cdot 10^{14} \mathrm{~cm}^{-2}$. Ослабление оже-сигнала подложки связано с уходом части молекул под графеновый слой, поскольку с графена, как уже говорилось выше, молекулы $\mathrm{C}_{60}$ полностью десорбируются. По уменьшению интенсивности ожесигнала молибдена (см. выше) нетрудно подсчитать, что под слой графена продиффундировала приблизительно каждая четвертая молекула $\mathrm{C}_{60}$, остальные молекулы десорбировались. Из рис. 4 видно также, что при образовании под графеном одного слоя из молекул фуллеренов процесс интеркалирования резко теряет свою эффективность и фуллерены перестают попадать под графен.

Как говорилось выше, углеродный пик в этих опытах слабо информативен, так как является суперпозицией оже-сигналов углерода от поверхности карбида МоС, объемного карбида $\mathrm{Mo}_{2} \mathrm{C}$, графена и от слоя молекул фуллерена под графеном.

\section{4. Обсуждение результатов}

Аналогично системам $\operatorname{Ir}(111)-$ графен и $\operatorname{Re}(1010)-$ графен молекулы $\mathrm{C}_{60}$ могут быть интеркалированы под графен на карбиде молибдена в количестве, соответствующем приблизительно одному слою. Опыты показали, что при $T=650 \mathrm{~K}$ только $\sim(20-25) \%$ молекул $\mathrm{C}_{60}$ уходят под слой графена, а бо́льшая их часть десорбируется. Сказанное выше, вероятно, связано с тем, что за время жизни на поверхности графена молекулы должны успеть промигрировать до дефекта графенового слоя, скорее всего до краев графеновых островков. Наличие краев графеновых островков неизбежно связано с самой природой образования слоя графена на металле. На поверхности нагретого металла в углеродном слое происходит фазовый переход первого рода типа конденсации и зарождаются двумерные графеновые островки [3]. При дальнейшем поступлении углеродного материала островки растут по площади, сливаются и образуют сплошную пленку графена с дефектами на краях слившихся островков [2,3].

Вероятный механизм интеркалирования графена чужеродными атомами описан в наших работах [1-3] и связан с термическим возбуждением краев островков. Вследствие термических флуктуаций происходит разрыв слабых межмолекулярных связей между валентнонасыщенным графеном и подложкой в некоторой части периметра островка. Это приводит к тому, что графеновый слой деформируется и край островка приподнимается, на некоторое время отдаляясь от подложки. Это в свою очередь позволяет большой молекуле $\mathrm{C}_{60}$ проникнуть под слой графена.

Эксперимент показывает, что молекулы фуллерена в интеркалированном состоянии занимают всю площадь под графеном, т.е. они способны к активной миграции в пространстве между графеном и подложкой. Как мы предполагаем, возбуждаться может любая часть островка графена, а не только его край. При этом возникает графеновый „пузырь“ (холм), расстояние графенметалл в этом месте увеличивается, что обеспечивает возможность продвижению молекул $\mathrm{C}_{60}$ под графеновой „крышей“, так как „пузыри“ все время рождаются и исчезают в любой точке пленки случайным образом даже при $T=300 \mathrm{~K}$.

Отметим, что интеркалируются чужеродными атомами не только сплошные пленки графена, но и островки графена любой площади [2].

Графеновая „крыша“ удерживает интеркалированные молекулы $\mathrm{C}_{60}$, не давая им десорбироваться в характерной для них области температур, так же, как она удерживает интеркалированные атомы. Например, в случае системы $\operatorname{Re}(1010)$-графен интеркалированный цезий десорбируется при крайне высокой температуpe, $T>2200 \mathrm{~K}($ !), при полном разрушении графенового слоя, хотя характерная область его десорбции как с металла, так и с внешней поверхности графена $\sim(700-800) \mathrm{K}[2]$. Судьба молекул $\mathrm{C}_{60}$ под слоем графена предрешена их диссоциацией на металле при $T \approx 900 \mathrm{~K}$ и графитизацией полученного углеродного слоя с дальнейшим ростом температуры.

Обратимся еще раз к рассмотрению механизма интеркалирования. Наши опыты с молекулами $\mathrm{C}_{60}$, а также с атомами, имеющими большие потенциалы ионизации (Al, $\mathrm{Ag}, \mathrm{C}, \mathrm{Cu}, \mathrm{Si}, \mathrm{Ba})$ показывают, что эффективное интеркалирование происходит только в некотором интервале температур $T_{1}<T<T_{2}$. При $T>T_{2}$ атомы или молекулы $\mathrm{C}_{60}$ эффективно десорбируются и не успевают промигрировать по поверхности графена до дефекта слоя. Напротив, при $T<T_{1}$ адсорбируемые атомы и молекулы $\mathrm{C}_{60}$ эффективно образуют на графене двумерные и трехмерные островки, являющиеся ловушками для поверхностной миграции. Для большинства указанных выше атомов интервал температур для эффективного интеркалирования составляет 900-1200 K, а для молекул $\mathrm{C}_{60}$ этот интервал узок, 650-700 K.

Просуммируем некоторые количественные данные, важные для методов электронной спектроскопии графена и фуллеренов.

1) Интенсивность оже-сигнала углерода $(E=272$ эВ) от толстой пленки графита в $(1.3 \pm 0.1)$ раза больше, чем от толстой пленки фуллерита.

2) Один слой графена уменьшает интенсивность ожесигнала подложки $(E=150-300$ эВ $)$ в $(1.6 \pm 0.1)$ раза.

3) Один слой из молекул фуллерена уменьшает интенсивность оже-сигнала подложки $(E=150-300$ эВ) в $(4.5 \pm 0.5)$ раза.

4) Интенсивность оже-сигнала углерода $(E=272$ эВ) от толстой пленки графита в $(2.6 \pm 0.2)$ раза больше, чем от одного слоя графена.

5) В пересчете на один атом углерода - его „чувствительность“ для оже-спектроскопии в $\sim 1.8$ раза больше в слое графена, чем в одном слое фуллерита, при расположении обеих структур на открытой поверхности подложки. 


\section{5. Заключение}

Таким образом, показано, что молекулы фуллерена $\mathrm{C}_{60}$ способны интеркалировать под однослойный графен на карбиде молибдена. Высокая интенсивность оже-пика подложки (Мо) позволила изучить этот процесс в деталях, которые были недоступны на ранее использованных подложках. Так, достоверно показано, что концентрация молекул $\mathrm{C}_{60}$ в интеркалированном слое не превышает монослойной ни при одном из использованных методов интеркалирования. В настоящее время непонятно, что является причиной, затрудняющей дальнейшее проникновения молекул $\mathrm{C}_{60}$ в интеркалированное состояние после достижения там их монослойной концентрации. Представляется интересным в научном и важным в практическом плане провести аналогичные эксперименты на других подложках, обладающих интенсивными пиками в электронных спектрах, чтобы понять степень универсальности обнаруженного эффекта

\section{Список литературы}

[1] Е.В. Рутьков, А.Я. Тонтегоде. УФН, 163, 57 (1993).

[2] N.R. Gall, E.V. Rut'kov. Physics and Applications of Graphene - Experiments (Intech Open Access Publisher, ISBN: 978-953-307-217-3, 2011) p. 293.

[3] N.R. Gall, E.V. Rut'kov, A.Ya. Tontegode. Int. J. Mod. Phys. B, 11 (16), 1865 (1997).

[4] E.V. Rut'kov, A.Ya. Tontegode, M.M. Usufov. Phys. Rev. Lett., 74 (5), 758 (1995)

[5] N.R. Gall, E.V. Rut'kov, A.Ya. Tontegode, M.M. Usufov. Mol. Mater., 7, 187 (1996).

[6] Hui Zhang, Qiang Fu, Yi Cui, Dali Tan, Xinhe Bao. J. Phys. Chem. C, 113, 8296 (2009).

[7] E. Grånäs, J. Knudsen, U.A. Schröder, T. Gerber, C. Busse, M.A. Arman, K. Schulte, J.N. Andersen, T. Michely. ASC Nano, 6, 9951 (2012).

[8] R. Larciprete, S. Ulstrup, P. Lacovig, M. Dalmiglio, M. Bianchi, F. Mazzola, L. Hornekær, F. Orlando, A. Baraldi, P. Hofmann, S. Lizzit. ASC Nano, 6, 9551 (2012).

[9] K. Sugavara, K. Kanetani, T. Sato, T. Takahushi. AIP Advances, 1, 022103 (2011).

[10] M. Sicot, Y. Fugot-Revurat, B. Kierren, G. Vasseur, D. Malterre. Appl. Phys. Lett., 105, 191603 (2014).

[11] L. Meng, R. Wu, H. Zhou, Y. Zhang, L. Li, Y. Wang. Appl. Phys. Lett., 100, 083101 (2012).

[12] L. Li, Y. Wang, L. Meng, R. Wu, H.J. Gao. Appl. Phys. Lett., 102, 093106 (2013).

[13] P. Sutter, J.T. Sadowsky, E.A. Suter. J. Am. Chem. Soc., 132, 8175 (2010).

[14] А.М. Шикин. Формирование, электронные структуры и свойства низкоразмерных структур на основе металлов (СПб, ВВМ, 2011) с. 430.

[15] N.R. Gall, E.V. Rut'kov. Physics and Applications of Graphene - Experiments (Intech Open Access Publisher, ISBN: 978-953-307-217-3, 2011) p. 209.

[16] Z. Waqar, I.V. Makarenko, A.N. Titkov, N.R. Gall, E.V. Rut'kov, A.Ya. Tontegode. J. Mater. Res. (JMR), 19 (4), 1058 (2004).
[17] Z. Kluzek, W. Kozlowski, Z. Waqar, S. Patta, J.S. BuenellGray, I.V. Makarenko, N.R. Gall, E.V. Rut'kov, A.Ya. Tontegode, A.N. Titkov. Appl. Surf. Sci., 252, 1221 (2005).

Редактор Л.В. Шаронова

\section{Intercalation of $\mathbf{C}_{60}$ fullerene molecules under monolayer graphene on molybdenum carbide}

\section{E.V. Rut'kov, N.R. Gall}

loffe Institute, 194021 St. Petersburg, Russia 